\title{
'Sticky spots' and subglacial lakes under ice streams of the Siple Coast, Antarctica
}

\author{
Olga V. SERGIENKO, ${ }^{1}$ Christina L. HULBE ${ }^{2}$ \\ ${ }^{1}$ Atmospheric and Oceanic Sciences Program, Princeton University/Geophysical Fluid Dynamics Laboratory, \\ 201 Forrestal Road, Princeton, NJ 08540, USA \\ E-mail: osergien@princeton.edu \\ ${ }^{2}$ Department of Geology, Portland State University, 1721 SW Broadway, Portland, OR 97201, USA
}

\begin{abstract}
Locations of subglacial lakes discovered under fast-moving West Antarctic ice streams tend to be associated with topographic features of the subglacial bed or with areas that have strong variations in basal conditions. Inversion of ice-stream surface velocity indicates that basal conditions under ice streams can be highly variable and that there can be widespread regions where basal traction is high. To seek an explanation for why lakes appear to be sited near areas with high basal traction, we use numerical models to simulate ice-stream dynamics, thermodynamics and subglacial water flow. We demonstrate that the ice flow over high basal traction areas produces favourable conditions for the ponding of meltwater. Energy dissipation associated with ice sliding over a region with high basal traction constitutes a water source supplying a lake, and ice-thickness perturbations induced by ice flow over variable traction create local minima in hydraulic potential. Variations in thermodynamic processes caused by such ice flow could be responsible for limiting the horizontal extent of the subglacial lakes.
\end{abstract}

\section{INTRODUCTION}

Among the numerous discoveries made possible by the Ice, Cloud and land Elevation Satellite (ICESat) Geoscience Laser Altimetry System (GLAS), probably the most unexpected was the existence of spatially confined short-term surface elevation changes attributed to dynamism of subglacial lakes. Fricker and others (2007) have identified several relatively large areas $\left(\sim 50-330 \mathrm{~km}^{2}\right)$ on Whillans and Mercer Ice Streams (subglacial lakes Conway, Engelhardt, Mercer and Whillans) that experienced variations of the order of metres in their surface elevation over a period of several months. A comprehensive analysis of the ICESat data (Smith and others, 2009) revealed that such short-term (months to years) elevation changes are widespread around Antarctica, and roughly 120 additional subglacial lakes of small spatial scale $(2-10 \mathrm{~km})$ were identified. A striking feature of these subglacial lakes is their clustering within the confines of ice streams and fast-flowing glaciers (Smith and others, 2009, figs 1 and 4).

Detailed studies of subglacial lakes below ice streams (Fricker and others, 2007, 2010; Fricker and Scambos, 2009) reveal that they are located near either topographic features such as ice ridges (Conway or Engelhardt) or near areas of sharp changes in basal conditions (Lake 10 on Whillans Ice Stream (WIS) and lakes Mac1-3 on MacAyeal Ice Stream). The most prominent example is probably Lake 10 on WIS. It is located upstream of so-called Ice Rise ' $\mathrm{A}$ ', a region of higher basal friction ('sticky spot') that was originally, and mistakenly, identified as an ice rise (Shabtaie and others, 1987; personal communication from D.R. MacAyeal, 2009). Ice Rise ' $\mathrm{A}$ ' is a unique feature for several reasons. It acts as a nucleation spot of the slip phase of the WIS stick/slip cycle (Wiens and others, 2008), consisting of a phenomenon whereby the ice stream experiences a very brief but rapid surge of otherwise almost stagnant ice-stream flow. Stick/slip has been observed exclusively on WIS (Bindschadler and others, 2003; Wiens and others, 2008; Winberry and others, 2009) and attributed to its multi-decadal slowdown trend (Sergienko and others, 2009). Although there might be a connection between the location of Lake 10 and the initiation of the stick/slip events at Ice Rise ' $A$ ', this connection cannot be firmly established due to the very low temporal resolution of the ICESat track profiles ( 90 days) compared to the timescale of stick/slip events ( 12-18 hours).

Of the five subglacial lakes identified on MacAyeal Ice Stream (Fricker and others, 2010), three are located downstream of the areas with enhanced basal traction (sticky spots) estimated by means of inverse methods. As Fricker and others (2010) suggest, formation of these subglacial lakes might be associated with dynamic effects of ice flow over the bed with spatially variable basal conditions.

There is a range of mechanisms that includes strong interconnection between ice dynamics and subglacial water dynamics. For instance, Bindschadler and Choi (2007) attribute acceleration of ice-stream tributaries to positive feedback between ice dynamics and water ponding. It is also possible that the locations of subglacial lakes in the vicinities of sticky spots could be a cause rather than an effect of the sticky spot. A low in hydraulic potential forces meltwater produced by the frictional energy dissipation to pond at some location, thus depleting other locations of basal water; basal traction must then increase and they are turned into sticky spots. Treatment of these effects is, however, beyond the scope of the present study.

Here we build upon ideas proposed by Fricker and others (2010) and advance them by considering the effects of thermodynamics and water pressure in a subglacial lake. We use numerical models simulating ice-stream dynamics and thermodynamics coupled to a subglacial water-flow model to complete this study. 


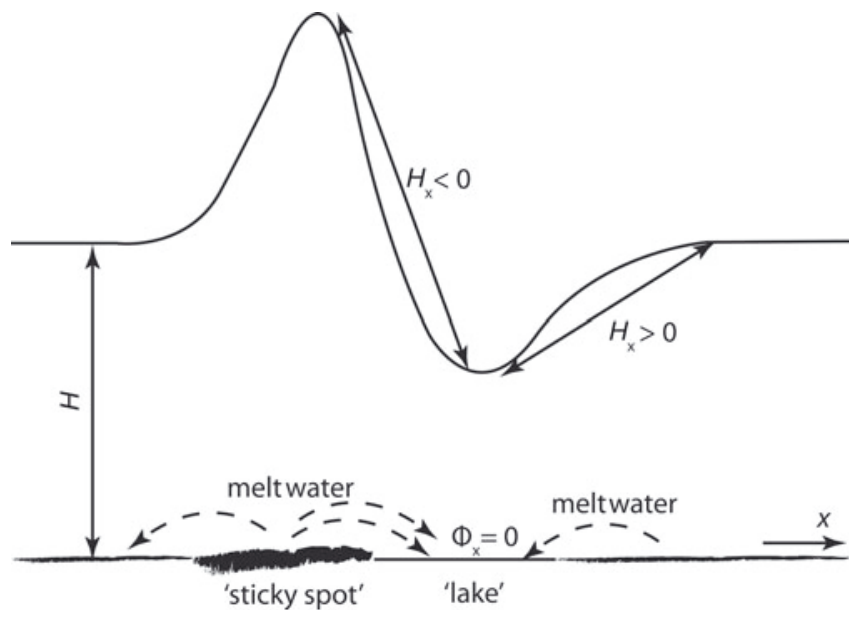

Fig. 1. Schematic depiction of ice-stream flow over 'sticky spot'lake-regular bed. If variations in basal topography are small, the gradient of hydraulic potential $\Phi_{x}$ is primarily determined by the ice-thickness gradient. The ice-thickness gradient is due to variations in the ice-flow velocity caused by the variations in basal traction. Note that the depicted situation is independent of a direction of ice flow.

\section{ICE STREAM AND SUBGLACIAL WATER FLOW IN THE VICINITY OF A STICKY SPOT}

Fricker and others (2010) have pointed out that, in addition to being a local source of the meltwater produced by the high frictional energy dissipation, sticky spots cause fairly strong gradients in the ice thickness. Thicker ice can be found over the sticky spot and thinner ice upstream and downstream of it. This thickness variation occurs because ice flows more slowly over the sticky spot and therefore cannot transport mass as fast as it does upstream or downstream of the sticky spot (Sergienko and others, 2007).

Water flow is controlled by the hydraulic potential

$$
\Phi=p_{\mathrm{w}}+\rho_{\mathrm{w}} \mathrm{g} z,
$$

where $\rho_{\mathrm{w}}$ is the water density, $\mathrm{g}$ is the acceleration due to gravity, $z$ is elevation above some datum (e.g. bed elevation $z_{\mathrm{B}}$ ) and $p_{\mathrm{w}}$ is the water pressure, which is usually approximated by the ice overburden (e.g. Clarke, 2005).

Subglacial water flows down the gradient of hydraulic potential $\Phi$. As evident from Equation (1) (assuming $p_{\mathrm{w}} \approx \rho_{\mathrm{i}} \mathrm{g} H$, where $\rho_{\mathrm{i}}$ is the ice density and $H$ is the ice thickness), the gradient of the ice surface elevation is significantly more important than the gradient of the bed elevation (Clarke, 2005). In locations where the gradient of the basal elevation is the same, water flows from locations of thicker ice to those of thinner ice. The ice-thickness gradient is larger when the gradient in the basal shear is larger. Therefore, a large ice-thickness gradient can be achieved when a subglacial lake is located adjacent to a sticky spot.

When ice flow transitions from flowing over the subglacial lake to flow over the ice bed with ambient basal shear (nonzero basal shear but less than that over the sticky spot), the ice thickness increases for the reasons described above. Hence, ice flow over basal conditions of sticky spotsubglacial lake-ambient basal shear (or in the reverse direction) causes the ice-thickness gradient to change sign from negative to positive (Fig. 1).

Unless the bed elevation gradient is significantly large, which is not the case for MacAyeal Ice Stream or WIS
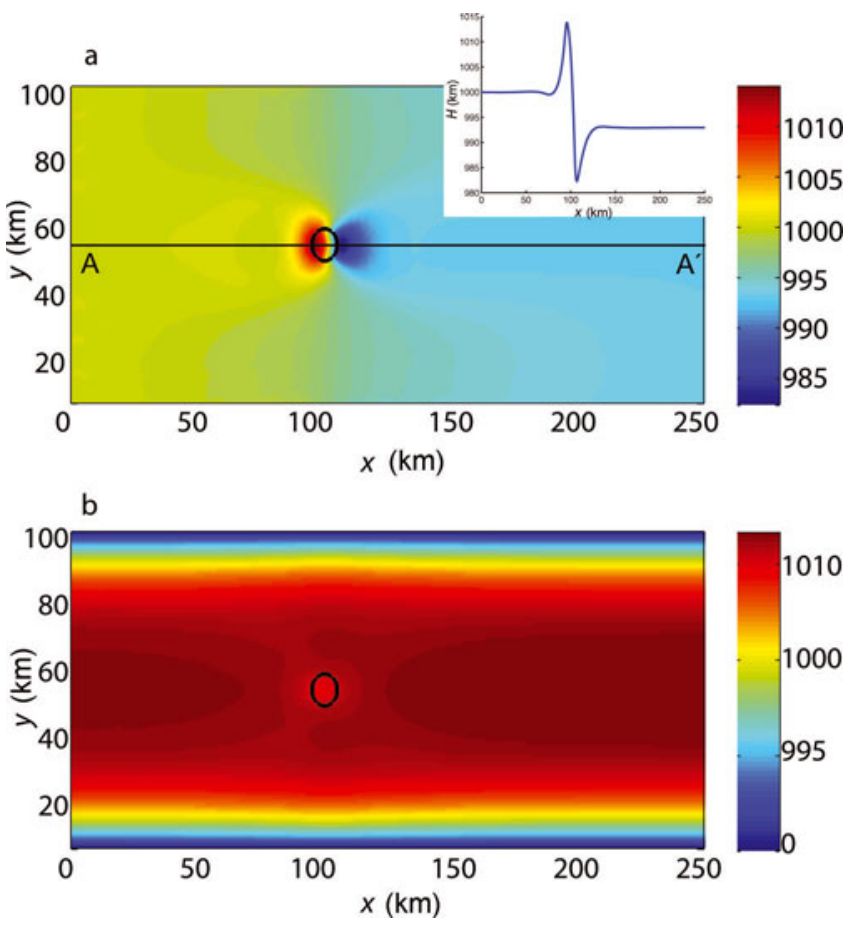

Fig. 2. Steady-state ice-stream flow over a sticky spot. (a) Ice thickness (m); (b) ice speed $\left(\mathrm{m} \mathrm{a}^{-1}\right)$. Inset in (a) shows ice thickness along a cross section $\mathrm{AA}^{\prime}$ shown in (a). The black circle shows the location of the sticky spot. Basal shear stress is $50 \mathrm{kPa}$ at the sticky spot and $10 \mathrm{kPa}$ elsewhere. Direction of ice flow is from left to right.

(Subglacial Lake Whillans and Lake 10 are located on the Whillans Ice Plain), the hydraulic potential gradient also changes sign; it is hence zero somewhere near the subglacial lake. Zero gradient of the hydraulic potential is a condition for water ponding, so formation of a subglacial lake near a sticky spot has a positive feedback. This suggests that a lake location is stable and, if drained, the lake could re-form and exhibit oscillatory behaviour.

To support these considerations, we conduct numerical experiments that address flow over a sticky spot for an idealized geometry. The numerical model and the geometry are the same as those developed by Sergienko and others (2007). The geometry is a rectangular domain, $250 \mathrm{~km}$ long and $100 \mathrm{~km}$ wide, with a circular patch $10 \mathrm{~km}$ in diameter that represents a sticky spot. The ice flow is simulated with vertically integrated momentum equations (MacAyeal, 1989) and assumes that basal resistance has plastic rheology (Tulaczyk and others, 2000) and basal shear stress is $10 \mathrm{kPa}$ everywhere (except the sticky-spot patch, where it is $50 \mathrm{kPa}$ ). These values of the basal shear stress are similar to those estimated by Joughin and others (2004a) and updated by Fricker and others (2010, fig. 9) using inverse methods. The ice-thickness distribution is calculated from the massbalance equation assuming no net ablation/accumulation at the ice surface.

Figure 2 shows the steady-state distributions of ice thickness and ice speed. Ice flow over the sticky spot is $\sim 12 \%$ slower than flow upstream or downstream of the sticky spot. This slowing of the ice flow is accompanied by a variation in the ice thickness where the ice is thicker over the sticky spot and thinner downstream of the sticky spot. Due to this thickness variation, the hydraulic potential is higher over the sticky spot and lower downstream of it. As a result, 


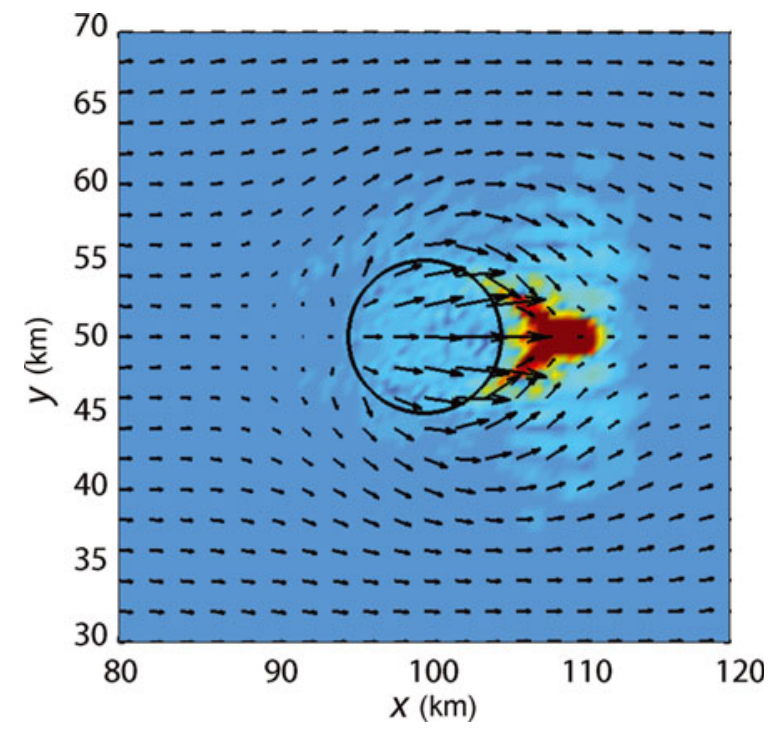

Fig. 3. Water flow from the sticky spot. Colour shows concentration of the meltwater produced over the sticky spot outlined by a black line. Black arrows are the negative gradient of hydraulic potential $\Phi$, show the direction of water flow and are proportional to the water velocity $\vec{u}_{\mathrm{w}}$.

meltwater produced over the sticky spot flows downstream and ponds in the hydraulic potential depression immediately downstream.

Figure 3 shows the spatial distribution and flow direction of the meltwater. The water flow is simulated under the assumption that it flows in a sheet-like style (e.g. Clarke, 2005) and the flow velocity is proportional to the gradient of the hydraulic potential $\Phi$, i.e.

$$
w_{t}+\vec{\nabla} \cdot\left(\vec{u}_{w} w\right)=\dot{M},
$$

where $w$ is the thickness of the water sheet, $w_{t}$ is a partial derivative of $w$ with respect to time, $\vec{u}_{\mathrm{w}}$ is the water velocity and $\dot{M}$ is the melting/refreezing rate. The water velocity $\vec{u}_{\mathrm{w}} \sim \vec{\nabla} \Phi$. Formulations for $\vec{u}_{\mathrm{w}}$ are:

$$
\vec{u}_{\mathrm{w}}=-\frac{K}{\rho_{\mathrm{w}} \mathrm{g}} \vec{\nabla} \Phi
$$

(Clarke, 2005) and

$$
\vec{u}_{\mathrm{w}}=-\frac{w^{2}}{12 \mu_{\mathrm{w}}} \vec{\nabla} \Phi,
$$

(Weertman, 1966; Le Brocq and others, 2009) where $K$ is the hydraulic conductivity of a water sheet and $\mu_{\mathrm{w}}$ is water viscosity.

These formulations produce similar spatial distributions of subglacial water ponding. They also suggest that the upstream or downstream sides of sticky spots are likely to be locations for the formation of subglacial lakes. Icethickness distribution shown in Figure 2a has a strong spatial gradient upstream of the sticky spot; however, the chosen bed topography (a uniform slope of $10^{-3}$ ) is such that the meltwater ponds downstream of the sticky spot. Therefore, the spatial gradients in ice thickness caused by ice flow over sticky spots create conditions favourable for the subglacial lake formation although basal topography determines the specific location of a lake, i.e. a location where the gradient of hydraulic potential is zero.

\section{THERMODYNAMIC EFFECTS}

We now turn to thermodynamic processes associated with ice flow over a sticky spot and subglacial lake formation adjacent to it. The temperature evolution is simulated by the standard heat diffusion-advection equation that only accounts for vertical heat diffusion (e.g. Pattyn, 2003). Temperature is prescribed as for boundary conditions: a constant atmospheric temperature of $-20^{\circ} \mathrm{C}$ at the ice top surface, and pressure-melting point at the bottom surface. We consider the evolution of the melting/refreezing rate $\dot{M}$ which is defined:

$$
\dot{M}=\frac{1}{L \rho_{\mathrm{i}}}\left(k_{\mathrm{i}} T_{z}+G+\vec{\tau} \cdot \vec{u}\right),
$$

where $L$ is the specific latent heat of fusion, $k_{\mathrm{i}} T_{z}$ is the energy flux into ice ( $k_{\mathrm{i}}$ is the ice heat conductivity and $T_{z}$ is the vertical gradient of ice temperature), $G$ is the geothermal heat flux and $\vec{\tau} \cdot \vec{u}$ is the frictional energy. For the chosen parameters of $\tau$ and values of $T_{z}$ observed on ice streams (Joughin and others, 2004b), the melting rate $\dot{M}$ over the sticky spot is primarily determined by the frictional energy.

For ice flowing over the lake, $\dot{M}$ changes sign and the ice experiences refreezing instead of melting. The reasons for this are:

1. Ice is separated from its bed by ponding meltwater; frictional energy of ice contact against the bed is therefore not produced.

2. For the same reason the geothermal flux is not supplied to the ice. The second and third terms of Equation (4) are therefore 0 .

3. Variations in ice thickness caused by ice flow over the bed with variable traction affect ice temperature distribution. Figure 4 shows vertical distributions of ice temperature $T$ and vertical temperature gradient $T_{Z}$ along the cross section $\mathrm{AA}^{\prime}$ shown in Figure 2a. As Figure 4a shows, ice flow over the sticky spot perturbs the isotherms. More importantly for melting/refreezing, ice flow decreases the vertical temperature gradient over the sticky spot and increases the temperature gradient. The heat flux to the ice downstream of the sticky spot is therefore increased.

4. The meltwater produced over the sticky spot is colder than the ice under which it ponds. This is because the temperature at which the ice starts to melt is a function of pressure: for every $1 \mathrm{~km}$ of ice, the melting point decreases by $\sim 1^{\circ} \mathrm{C}$ (Paterson, 1994). Therefore, the pressure-melting point for the thicker ice is lower than for the thinner ice. This implies that, for a subglacial lake situated next to a sticky spot, meltwater produced by ice flowing over the sticky spot is colder than the pressuremelting point of ice over the subglacial lake, i.e. it is supercooled. (The effects of hydraulic supercooling were extensively discussed in the context of accretion of debris-filled ice on the glacier bases (e.g. Alley and others, 1998).) Most likely, the supercooling state of meltwater filling the subglacial lake is thermodynamically unstable.

All these considerations suggest that there is strong refreezing on the roof of the subglacial lake. The effects of supercooling could be reduced by geothermal flux heating water in the lake from below (Thoma and others, 2010). 
However, we consider the 'open lake', i.e. the lake is constantly filled with water produced over the sticky spot. As stated above, the meltwater produced over the sticky spot is colder than the lake roof; it therefore sinks to the bottom of the lake due to low buoyancy. The water temperature in the lake is determined by two competing sources of heating and cooling: heating by geothermal flux and cooling due to the influx of cold water produced over the sticky spot. Parameters that determine the water temperature in the lake are water temperature diffusivity (the ratio of the heat conductivity to heat capacity and density) and meltwater influx into the lake.

A subglacial lake will continue to grow if the the meltwater production over the sticky spot exceeds the refreezing rate at the lake roof, i.e.

$$
\int_{A_{\text {stsp }}} \mathrm{d} A \dot{M}_{\text {stsp }}>\int_{A_{\text {lake }}} \mathrm{d} A \dot{M}_{\text {lake, }}
$$

where $A_{\text {stsp }}$ and $A_{\text {lake }}$ are surface areas of the sticky spot and the lake, respectively.

This would probably be the case for a number of sticky spots, because the increase in the vertical temperature gradient is $\sim 10-20 \%$ (Fig. $4 \mathrm{~b}$ ) and because the meltwater supercooling is $\sim 0.03-0.05^{\circ} \mathrm{C}$. Also, as Figure 3 shows, the surface area of the hydraulic depression where the meltwater concentrates is smaller than the surface area of the sticky spot where the meltwater is produced. A spatial extension of the lake, $A_{\text {lake, }}$ could be limited if the freezing rate is larger than the local influx of meltwater, $\vec{u}_{\mathrm{w}} w$. The important finding is that the spatial extent of the lake is controlled by both dynamic and thermodynamic processes.

\section{LIMITS OF THE MODEL}

The present ice-stream/subglacial flow model could be considered as 'diagnostic' in the context of a subglacial lake that forms near a sticky spot. Assumptions of both the iceflow and the water-flow models used here are too restrictive to allow 'prognostic' considerations.

For instance, the presented model cannot be used to simulate subglacial lakes with pressure substantially different from the ice overburden pressure: the subglacial flow model would require detailed knowledge of the waterpressure evolution. Similarly, a sealed subglacial lake, i.e. one which does not have a constant throughput of water, cannot be adequately simulated. A seal could be formed either in circumstances where the ice overburden pressure is much larger than the water pressure or where ice is frozen to the bed immediately beyond the boundary of the lake. The former would again require a different water-flow model and the latter would violate the ice-dynamic model assumption of zero vertical shear stresses.

A complete evolution of a subglacial lake under an ice stream would require detailed consideration of all stress components in the ice stream and evolution of the pressure in a subglacial lake.

Drainage of subglacial lakes under ice streams also requires special treatment. Existing theories of subglacial lake discharge, based on ideas proposed by Weertman (1972) and Nye (1976) and later developed in numerous studies successfully applied to lake drainage under slowmoving ice (e.g. Walder and Fowler, 1994; Fowler, 1999; Evatt and others, 2006; Evatt and Fowler, 2007; Carter and others, 2009), cannot be directly applied to the discharge of
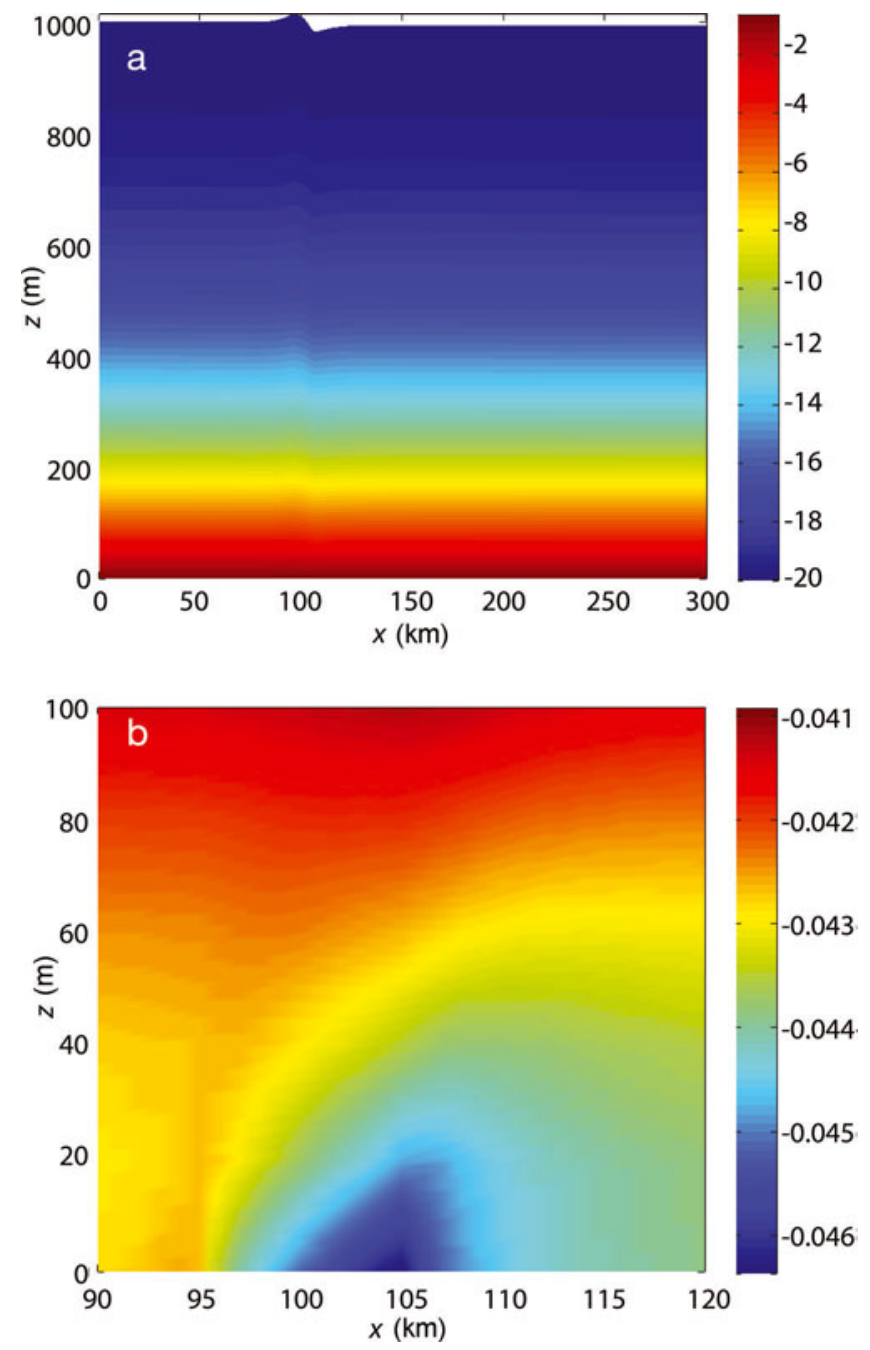

Fig. 4. Effects of ice thickness variations on temperature along cross section $\mathrm{AA}^{\prime}$ shown in Figure 2a. (a) Vertical temperature distribution $\left({ }^{\circ} \mathrm{C}\right)$; and (b) vertical temperature gradient $\left({ }^{\circ} \mathrm{Cm}^{-1}\right)$ in bottom $100 \mathrm{~m}$.

subglacial lakes under fast-flowing ice streams. Primarily, these theories treat ice as an infinite medium with shearing as a primary form of deformation. Ice streams are believed to be deformed through longitudinal extension or compression. In addition, a delicate balance between driving stress and basal shear stress specific to the ice-stream flow, as well as strong non-locality of its mass balance, could play an important role in subglacial-lake drainage.

These considerations suggest that a theory of evolution of subglacial lakes under ice streams, in particular one which accounts for specific aspects of ice-stream dynamics (i.e. differences between ice-stream flow and slow inland ice flow), is required to adequately describe the ice-stream/ subglacial-lake interaction.

\section{CONCLUSIONS}

Using a coupled model of ice-stream/subglacial water flow, we have demonstrated that ice flow over a sticky spot creates favourable conditions for water ponding and formation of a subglacial lake.

While the specific location of the lake is primarily determined by the bed topography, the dynamics demonstrated by the study indicate that sub-ice-stream lakes are 
preferentially located either upstream or downstream of sticky spots. The existence of Lake 10 on Whillans Ice Stream and the lakes Mac 1-3 on MacAyeal Ice Stream could therefore be due to the influence of nearby sticky spots that are indeed observed in the vicinity.

The ice flow over a sticky spot significantly affects ice thermodynamics, not only through the high frictional energy dissipation at the ice bed but also through the distortions of the vertical temperature gradient in ice. The meltwater filling a subglacial lake can be supercooled, and may support strong refreezing on the roof of the lake. It is also possible that a seal at the edges of the lake could form due to refreezing.

\section{ACKNOWLEDGEMENTS}

This study is supported by US National Science Foundation grants OPP-0838811 and ARC-0934534. We thank D. MacAyeal and two anonymous reviewers for valuable comments and constructive criticism.

\section{REFERENCES}

Alley, R.B., D.E. Lawson, E.B. Evenson, J.C. Strasser and G.J. Larson. 1998. Glaciohydraulic supercooling: a freeze-on mechanism to create stratified, debris-rich basal ice: II. Theory. J. Glaciol., 44(148), 563-569.

Bindschadler, R. and H. Choi. 2007. Increased water storage at icestream onsets: a critical mechanism? J. Glaciol., 53(181), 163-171.

Bindschadler, R.A., M.A. King, R.B. Alley, S. Anandakrishnan and L. Padman. 2003. Tidally controlled stick-slip discharge of a West Antarctic ice stream. Science, 301(5636), 1087-1089.

Carter, S.P., D.D. Blankenship, D.A. Young, M.E. Peters, J.W. Holt and M.J. Siegert. 2009. Dynamic distributed drainage implied by the flow evolution of the 1996-1998 Adventure Trench subglacial outburst flood. Earth Planet. Sci. Lett., 283(1-4), 24-37.

Clarke, G.K.C. 2005. Subglacial processes. Annu. Rev. Earth Planet. Sci., 33, 247-276.

Evatt, G.W. and A.C. Fowler. 2007. Cauldron subsidence and subglacial floods. Ann. Glaciol., 45, 163-168.

Evatt, G.W., A.C. Fowler, C.D. Clark and N.R.J. Hulton. 2006. Subglacial floods beneath ice sheets. Philos. Trans. R. Soc. London, Ser. A, 364(1844), 1769-1794.

Fowler, A.C. 1999. Breaking the seal at Grímsvötn, Iceland. J. Glaciol., 45(151), 506-516.

Fricker, H.A. and T. Scambos. 2009. Connected subglacial lake activity on lower Mercer and Whillans Ice Streams, West Antarctica, 2003-2008. J. Glaciol., 55(190), 303-315.

Fricker, H.A., T. Scambos, R. Bindschadler and L. Padman. 2007. An active subglacial water system in West Antarctica mapped from space. Science, 315(5818), 1544-1548.

Fricker, H.A., T. Scambos, S. Carter, C. Davis, T. Haran and I. Joughin. 2010. Synthesizing multiple remote-sensing techniques for subglacial hydrologic mapping: application to a lake system beneath MacAyeal Ice Stream, West Antarctica. J. Glaciol., 56(196), 187-199.

Joughin, I., D.R. MacAyeal and S. Tulaczyk. 2004a. Basal shear stress of the Ross ice streams from control method inversion. J. Geophys. Res., 109(B9), B09405. (10.1029/2003JB002960.)

Joughin, I., S. Tulaczyk, D. MacAyeal and H. Engelhardt. 2004b. Melting and freezing beneath the Ross ice streams, Antarctica. J. Glaciol., 50(168), 96-108.

Le Brocq, A.M., A.J. Payne, M.J. Siegert and R.B. Alley. 2009. A subglacial water-flow model for West Antarctica. J. Glaciol., 55(193), 879-888.

MacAyeal, D.R. 1989. Large-scale ice flow over a viscous basal sediment: theory and application to Ice Stream B, Antarctica. J. Geophys. Res., 94(B4), 4071-4087.

Nye, J.F. 1976. Water flow in glaciers: jokulhlaups, tunnels and veins. J. Glaciol., 17(76), 181-207.

Paterson, W.S.B. 1994. The physics of glaciers. Third edition. Oxford, etc., Elsevier.

Pattyn, F. 2003. A new three-dimensional higher-order thermomechanical ice-sheet model: basic sensitivity, ice stream development, and ice flow across subglacial lakes. J. Geophys. Res., 108(B8), 2382. (10.1029/2002JB002329.)

Sergienko, O.V., D.R. MacAyeal and R.A. Bindschadler. 2007. Causes of sudden, short-term changes in ice-stream surface elevation. Geophys. Res. Lett., 34(22), L22503. (10.1029/ 2007GL031775.)

Sergienko, O., D.R. MacAyeal and R.A. Bindschadler. 2009. Stickslip behavior of ice streams: modeling investigations. Ann. Glaciol., 50(52), 87-94.

Shabtaie, S., I.M. Whillans and C.R. Bentley. 1987. The morphology of Ice Streams A, B, and C, West Antarctica, and their environs. J. Geophys. Res., 92(B9), 8865-8883.

Smith, B.E., H.A. Fricker, I.R. Joughin and S. Tulaczyk. 2009. An inventory of active subglacial lakes in Antarctica detected by ICESat (2003-2008). J. Glaciol., 55(192), 573-595.

Thoma, M., K. Grosfeld, C. Mayer and F. Pattyn. 2010. Interaction between ice sheet dynamics and subglacial lake circulation: a coupled modelling approach. Cryosphere, 4(1), 1-12.

Tulaczyk, S.M., B. Kamb and H.F. Engelhardt. 2000. Basal mechanics of Ice Stream B, West Antarctica. I. Till mechanics. J. Geophys. Res., 105(B1), 463-481.

Walder, J.S. and A. Fowler. 1994. Channelized subglacial drainage over a deformable bed. J. Glaciol., 40(134), 3-15.

Weertman, J. 1966. Effect of a basal water layer on the dimensions of ice sheets. J. Glaciol., 6(44), 191-207.

Weertman, J. 1972. General theory of water flow at the base of a glacier or ice sheet. Rev. Geophys. Space Phys., 10(1), 287-333.

Wiens, D.A., S. Anandakrishnan, J.P. Winberry and M.A. King. 2008. Simultaneous teleseismic and geodetic observations of the stick-slip motion of an Antarctic ice stream. Nature, 453(7196), 770-774

Winberry, J.P., S. Anandakrishnan, R.B. Alley, R.A. Bindschadler and M.A. King. 2009. Basal mechanics of ice streams: Insights from the stick-slip motion of Whillans Ice Stream, West Antarctica. J. Geophys. Res., 114(F1), F01016. (10.1029/ 2008JF001035.) 